\title{
Methods to the Prediction of Phase Behavior Predicting Phase Behavior With Digital Computers
}

\author{
T. J. CONNOLLY \\ S. P. F R A N E L \\ B. H. SAGE
}

$\mathrm{C}_{\mathrm{cos}}$

OMMERCIALLY AVAILABLE digital computing equipment of the punch-card type ${ }^{1,2}$ permits the expeditious direct application of relatively complex analytical expressions to the evaluation of the conventional thermodynamic properties of pure substances and mixtures. In the case of hydrocarbons, the Benedict equation ${ }^{3,4}$ is of particular utility in describing the effect of pressure, temperature, and composition upon the thermodynamic properties of a system. However, the complexity of such an expression makes this application time-consuming unless automatic computing equipment is employed. Beattie ${ }^{5}$ has outlined the general nature of the calculations associated with the evaluation of the thermodynamic properties of homogeneous and heterogeneous systems. These methods apply to pure substances and multicomponent systems alike.

At present it appears practical to utilize equations of state to establish the desired thermodynamic properties of pure substances or mixtures at the time they are required for a particular application. A number of books would be required to record briefly the pertinent thermodynamic properties of the pure substances of common industrial interest, and a small library would be necessary to record the pertinent phase behavior and relevant thermodynamic properties of mixtures encountered in industrial practice. The simple generalizations which have been proposed to describe the behavior of components and their mixtures are inadequate for many purposes. The combination of automatic digital computing equipment and suitable equations of state appears to be one means of obtaining values of volume, enthalpy, and entropy as a function of state for homogeneous systems and the composition of the coexisting phases in the heterogeneous region without the need for extensive tabulations associated with the recording of such data. The use of equations of state represents a significant improvement in accuracy over that normally realized with simple generalizations which usually are based, at least in part, on the theorem of corresponding states. The Benedict equation of state which is explicit in pressure may be written in the following form:

$$
\begin{aligned}
P=\frac{R T}{V}+\left[B_{0} R T-A_{0}-\frac{C_{0}}{T^{2}}\right] \frac{1}{V^{2}}+ & {[b R T-a] \frac{1}{V^{3}}+} \\
& {\left[\frac{c}{T^{2}}\left(1+\frac{\gamma}{V^{2}}\right) \exp \left(-\frac{\gamma}{V^{2}}\right)\right] \frac{1}{V^{3}}+\frac{a \alpha}{V^{6}} }
\end{aligned}
$$

where $P$ is pressure in pounds per square inch absolute, $R$ is the molal gas constant, $T$ is temperature in degrees

Digest of paper 50-259, Application of Automatic Digital Computing Methods to the Ftedicticn of Phase Behavior," recommended by the AIEE Committee on Computing Devices and approved by the AIEE Technical Program Committee for presentation at the AIEE Fall General Meeting, Oklahoma City, Okla., October 23-27, 1950. Not scheduled for publication in AIEE Transactions.

T. J. Connolly, S. P. Frankel, and B. H. Sage are all with the California Institute of Technology, Pasadena, Calif

This paper is a contribution from the American Petroleum Institute Research Project 3? located at the California Institute of Technolcgy. The interest and assistance of $W$. $N$ Lacev in the preparation of the basic manuscript is acknowledged.
Rankin, and $V$ is molal volume in cubic feet per pound of molecular weight. Parameters in the equation are $A_{0}$, $B_{0}, C_{0}, a, b, c, \alpha$, and $\gamma$. Similar expressions of somewhat greater complexity based upon equation 1 are available to establish the enthalpy, entropy, and fugacity ${ }^{6}$ of a phase as a function of volume, temperature, and composition.

Effective calculations of this nature involved the use of punch-card digital computing equipment ${ }^{1,2}$ including the type-604 electronic computing punch developed by the International Business Machines Corporation. It is possible to establish the volume, enthalpy, entropy, and fugacity of a phase in not more than five minutes of computing effort, providing the requisite background data are at hand. The latter information involves a knowledge of the several constants of the equation of state indicated in equation 1 and the requisite interaction coefficients for mixtures. Such information has been obtained for the lighter paraffin hydrocarbons $s^{3,4}$ and a number of other compounds. The details of such calculations are available. $^{7}$

The rather extensive iterative procedures required to determine the composition of the coexisting phases in the case of a ternary mixture involved about 40 minutes of computing time. It is probable that this period may be decreased as further developments are made on the computing equipment and techniques. These calculations include the determination of the thermodynamic properties of the coexisting phases as well as their composition. The use of a card-control calculator or a general purpose electronic computer would result in a substantial decrease in the time required for these iterative procedures.

The direct utilization of digital computing equipment to evaluate the phase behavior and the thermodynamic properties of coexisting phases at the time they are desired avoids the need of extensive tabular records and yields results of somewhat better accuracy than the generalized predictions presently available.

\section{REFERENCES}

1. Punched Card Methods in Scientific Computation (bock), W. J Eckert. Columbia University Press, New York, N. Y., 1940.

2. Some Applications of Punched-Card Methods in Research Problems in Chemical Phvsics, G. W. King. Journal of Chemical Education (Easton, Pa.), volume 24, February 1947, pages 61-4.

3. An Empirical Equation for Thermodynamic Properties of Light Hydrocarbons and Their Mixtures. I: Methane, Ethane, Propane, and n-Butane, Manson Benedict, G. B. Webb, L. C. Rubin. Journal of Chemical Physics (New York, N. Y.), volume \&, April 1940, pages 334-45.

4. An Empirical Equation for Thermodynamic Properties of Light Hydrocarbons and Their Mixtures. II: Mixtures of Methane, Ethane, Propane, and n-Butane, Manece Benedict, G. B. Webb, L. C. Rubin. Journal of Chemical Physics (New York, N. Y.), volume 10, December 1942, pages 747-58.

5. The Computation of the Thermcdynamic Properties of Real Gases and Mixtures of Real Gases, J. A. Beattie. Chemical Reviewos (Baltimore, Md.), volume 44, 1949, pagea 141-92.

6 Thermodynamics and the Free Energy of Chemical Substances (book), G. N. Lewie, M. Randall. McGraw-Hill Book Company, Inc., New York, N. Y., 1923.

7. Application of Automatic Digital Computing Methods to the Prediction of Phave Behavior, T. J. Connolly, S. P. Frankel, B. H. Sage. American Documentation Institute, Washington, D. C., 1951. 